\title{
Outras histórias no litoral do mundo
}

\section{Tatiana Pequeno ${ }^{1}$}

\begin{abstract}
RESUMO: Em sua segunda trilogia publicada a partir dos anos oitenta, Maria Gabriela Llansol reconfigura o espaço aquático pró-colonialista. Hibridizando morfologicamente os principais personagens da História de Portugal, a autora propõe uma alternativa de fulgor ao projeto português. Neste artigo, investigaremos os procedimentos desta proposta além-humana e verificaremos suas implicaturas e verberações.
\end{abstract}

PALAVRAS-CHAVE: Literatura Portuguesa, Maria Gabriela Llansol, Política

ABSTRACT: In her second trilogy published at eighties, Maria Gabriela Llansol resets the water space pro-colonial. Rendering hybrid the main morphological characters in the History of Portugal, the author proposes an alternative of flash to the portuguese project. In this paper we will investigate the procedures of this beyond human proposal along with the looking at their implicatures and reverberations.

KEYWORDS: Portuguese Literature, Maria Gabriela Llansol, Politic

A distância é o percurso, e na globalidade do céu receio não descobrir viagem por mar que me oriente.

Maria Gabriela Llansol, Um Falcão no Punho.

Como falar de um paradigma sem recair nos seus clichês? Como tratar do "Mar Português" de glórias e fantasmagorias sem recorrer aos seus mitos e às tentativas de dissolução desses mesmos mitos? Cartografando a dialética poesia pessoana ortônima com a de Campos? Talvez antes, Cesário Verde já tenha esmiuçado o legado das varinas dos pobres bairros que, também como o poeta, foram deixados ao lugar de fora das salas e dos modos de ler, aristocraticamente, a História, sempre. Mas não apenas: já no próprio Camões Maria Gabriela Llansol enxerga Comuns, a metamorfose da lápide, versão 
fulgural e reapropriada para a energia que vaga à saída das nascentes do Tigre e do Eufrates para outra geografia natural: finisterra.

É nesse sentido ambíguo do lugar periférico que desejo auscultar o rumor dessas vozes que falam entre e sobre o Atlântico na segunda trilogia publicada por Maria Gabriela Llansol e intitulada "O Litoral do Mundo". Para tanto, primeiramente é necessário partir do óbvio e dizer o irremediável sobre o século XVI português e pensar que dele, e sobretudo de sua imagem, é que nasce o propósito d’Os Lusíadas. E em um um segundo momento, parece incontornável dizer que neste mesmo livro, a épica nuclear da língua portuguesa, ou melhor, no livro de linhagem que funda em diversos sentidos a própria língua também acontece de o Poeta reavaliar o próprio Canto e, no caso, mostrar as suas fraturas.

A zona limítrofe que é percebida na geografia desse contexto, isto é, a dimensão natural do que caracteriza o lugar de água ou o lugar da terra está necessariamente embutida no título da trilogia, muito embora essa ambiguidade seja diluída através da textura desse espaço limítrofe que Llansol já evoca para Causa Amante:

Com os textos escritos por Luís M., que não vêm sozinhos, desembarcarão também, por mar, aqueles a quem os Príncipes chamam marginais, e que são a genteprópria do nosso território, pois, por direito, nós herdamos as margens; acolher os marginais nas margens, que estão sempre em perigo, e em lenta evolução à beira do rio, mar, corrente de água, foi a idia que colhi no pano de rendas feitas por Eulália. Eu talvez não tenha muito tempo para aproximar-me dessa corrente de profundeza humana, que minhas irmãs devem cuidar até ser possível perfurmar-lhes a última chaga; eu, a tímida escrevente, talvez tenha de ficar muitas horas sentada em frente do meu banco, a contar para a posteridade, que é indeterminada, como as coisas se passaram neste cabo Espichel, e por ele tornaram a passar, no movimento ritmado das marés.

(LLANSOL, 1984b, p. 30-31) 
Se, portanto, as margens são os lugares nos quais as beguinas repousam do êxodo, é também notório que, por ser local de perigo conforme o excerto acima demonstra, a experiência das migrações se "rivaliza" com a fecundidade dessa herança, tendo em vista que é aí que ocorrerão diversas "cenas fulgor". Há uma preocupação narrativa de apontar, por exemplo, na figura de Clara Serena, que a chegada e a permanência dessa comunidade própria ocorrem sem combate, apesar de o léxico que opera esse trânsito ser eminentemente épico e, com isso, ser enseada "dessa corrente de profundeza humana" (LLANSOL, 1984b, p. 240). Esse legado, ápice da estruturação humanística do Ocidente, foi que deu origem ou permitiu inúmeras condições de barbárie, autorizadas, sobretudo, pelos argumentos cristãos dos jesuítas aliados aos propósitos de Estado do Príncipe e sua nobreza. E nisso, um dos propósitos da ultrapassagem de voltar à língua:

A água, de que se habituara a ouvir dizer que murmurava, indicava-lhe que um bando de pobres atravessaria, à hora do calor, a cidade de lés a lés, deslocando os brasões, fazendo desaparecer os livros das genealogias, destruindo as provas da outorga de tenças, pensões e cargos em frente do Paço Real.

(LLANSOL, 1998, p. 32)

O fragmento acima, retirado de Um Falcão no punho, diário que abarca o ano de 1979 e os projetos iniciais de Causa Amante, admite que é a água o nó central da cultura portuguesa e que sua hidráulica - versão talvez mais crua para a antiga mecânica dos fluidos - está necessariamente comprometida com a inoperância e com o atrofiamento da atividade criadora de pujança. É provável que, a esse respeito, seja possível pensar que a ideia de esperança para a memória cultural portuguesa esteja suficientemente coadunada a traços diretos da fratura deixada pela manhã que enfim não houve depois de AlcácerQuibir. Ou, em outras palavras: a dimensão insólita do principal ator da batalha, Dom Sebastião, absorveu o princípio esperança que está originalmente atrelado ao fundamento da criação e do prazer estético. 
Como Maria Gabriela Llansol tratou de tais problemas de maneira lateral (lembrar que este combate não poderia ser frontal) no sentido de que, para ela, havia outros ramos, seria fundamental perceber que, partindo de uma desconfiguração da própria condição de protagonista da História, Dom Sebastião metamorfoseia-se em um arbusto. Para integrar a Clave da Pequenez, por conseguinte, é forçoso destituir o humano como centralizador ou pivô dos afetos e das convivências, sobretudo com a estética:

Quando a noite desceu, Sebastião, que perdera o uso da palavra, e mantivera o uso de outra razão, vislumbrou o que era calar-se entre nós.

(...)

Quando todos os arbustos tinham sido arrancados e talhados, um suspiro de vaga natureza atravessou o carro grosseiro que os levava atraídos pelos novos cheiros; Alissubbo acompanhava, ao passo da mula, a pequena floresta inerte; e Coração de Urso permanecia ao alcance dos braços cortados para que Sebastião, o dom do arbusto, não sucumbisse na descida vegetal.

(LLANSOL, 1984b, p. 65-66, negritos meus)

Chamo a atenção para a duplicidade que o negrito sugere ao permitir e ao validar o entresser, mas também indicar que tal cena fulgor evoca o nó, em seu plural, do paradigma frontalmente inatacável que recorrentemente se usa para diagnosticar e tornar visíveis as amarras de uma sociedade, ou melhor, de um tipo de civilização em que o mito e o humano estão coadunados e a serviço de um projeto de Poder que não prescinde da polarização entre Senhor e Escravo.

É a partir disso que se verifica fundamentalmente uma influência nietzscheana que consiste em entender as civilizações judaico-cristãs como cernes da moral escrava, baseadas sempre nos princípios de submissão, expiação e servilismo, o que vai de encontro à perspectiva dos "espíritos livres". Talvez por causa disso, na já citada entrevista concedida a João Mendes (1995), Llansol afirme: "só o escravo pergunta quem é, o homem livre segue quem o chama". Com isso, apesar de haver uma lição de humildade, cujo sentido seria a 
experiência da pobreza por parte daqueles que irrompem na cultura como as chaves de ler o Império "assinalado", Llansol se afasta da moral puramente genealógica de Nietzsche, que previra apenas o humano e sua superdimensão como júbilo e potência, exatamente por crer na comunidade e propor a ela a ampliação das categorias biopoéticas. Ou seja, o fato de estar preocupada com a dimensão da servidão humana leva Llansol a enxergar que essa visão de servilismo também impede que animais e plantas sejam igualmente reduzidos a meros papéis passivos.

Por outro lado, seria o caso de pensar não apenas do ponto de vista sócio - histórico-civilizatório, já que as personagens épicas podem representar papéis que funcionam de maneira pouco precisa, uma vez que Sebastião é simplesmente grafado como dom ou dom arbusto e Camões como Comuns. Deve-se, sobretudo, observar que o primeiro, inúmeras vezes, aparece no texto em minúsculas, enquanto o segundo desliza e atravessa até o novo nome com a manutenção da maiúscula que lhe garante o nome próprio. Outro ponto fundamental é o que também sustenta este modo de ordenar eticamente "O Litoral do Mundo": Comuns não se pergunta quem é, e por isso mesmo é o agente ativo e executor do Poema, enquanto D. Sebastião, que em princípio teria a precedência da senhoria Real, é apenas matéria ou "sujeito" de lugar passivo para quem a Obra-mor em si é dedicada. Diz Llansol numa entrada de Um Falcão no Punho:

Hoje comecei um trabalho de sincretismo com Os Lusíadas; há um escolho tantos anos de lugar-comum de admiração coletiva; falei com o Augusto e, como eternamente, ele tenta ajudar-me a alcançar a parte serena da crise e sugere-me um programa de recolha das minhas intuições a partir d’Os Lusíadas.

(LLANSOL, 1998, p. 40)

Nesse sentido, seria correto afirmar que se há alguma precedência em relação ao Poeta, talvez seja pelo fato de nele predominar o aspecto estético da criação, e não porque seu grande livro investe na tonalidade épica d' "As navegações grandes que fizeram;”, $\mathrm{n}^{\prime}$ “[a] fama das vitórias que tiveram;/ (...)/ Que eu canto o peito ilustre Lusitano" (Lus, I, 3, 2-5). Além disso, é interessante 
notar que o desejo intuitivo de promover o "trabalho de sincretismo" consistiria basicamente em uma desautomatização precisa da Obra como tópica clichê a serviço da comoção e da "admiração coletiva". Noutras palavras: para Llansol, Os Lusíadas deve ser criteriosamente lido porque o seu pertencimento épico necessariamente alude a modos de subjugar, matar e morrer.

Próximo de tal questão, Jorge Fernandes da Silveira, em O Tejo é um Rio controverso (2008), sugere que a grandiloquência do herói insuflado seja menor que a voz camoniana manifestada através do que move o Amor e seus desdobramentos considerando, para tanto, três núcleos presentes nos Cantos III, V e X, respectivamente: o de Inês de Castro, o do Gigante Adamastor e o do peito lamentoso do Poeta. Aproveitando o sentido da causa amante que perpassa (talvez fosse melhor dizer atravessa) não apenas o discurso épico de Camões, mas também a sua lírica, poder-se-ia dizer que o desenvolvimento de Llansol em relação a novas criações de sentido para a figura camoniana reintegra o autor a um projeto de reconfiguração estética e cosmogônica², que decerto estará mais evidente em Contos do Mal Errante, segundo livro de "O Litoral do Mundo".

Preocupada também com a pergunta formulada em Um Falcão no Punho (1998, p. 34), "E se Vasco da Gama não tivesse voltado?", a autora aprofunda em Da Sebe ao Ser (1988) uma das cenas fulgor mais contundentes dos pontos de vista épico e lírico, quando narra o primeiro longo encontro entre Vê Gama e Comuns e por meio do qual se verifica a dissolução entre tipos de fronteiras, como a da superioridade da História em relação à Arte, por exemplo, que Llansol chamará de "cena fulgor audível". É interessante observar que por ser audível, o canal da discussão (oral) entre Gama e Comuns privilegia a palavra em confronto, e que apesar de aparentarem oposição, estão submetidas ao mesmo argumento teleológico: a dilatação da fé e do império e, por conseguinte, a Honra. Em um estudo citado pela própria Llansol em O Senhor de

2 É importante notar que ao longo dos três livros de "O Litoral do Mundo" haja insistência por parte da autora em utilizar um léxico comprometido com a orientação, como por exemplo "atravessar", "ocidente", "oriente", "em direção a" etc. 
Herbais, António Guerreiro ${ }^{3}$ alude a um ponto importante de Da Sebe ao Ser, quando repara que a tramitação das personagens para certa descaracterização histórica acaba por inseri-los na ambiência da Comunidade como alternativa a um projeto da Pátria Nacional, cujo telos é, finalmente, o Poder. A Comunidade, nesse caso, é o contínuo abraçamento, enquanto a Pátria é o resultado de uma política permanente de exclusões. A aposta em um projeto comunitário de congraçamento acaba gerando um efeito sincrético de uma política como “associações da diferença" (ARENDT, 2005). Nisso Llansol também acerta, porque desloca Os Lusíadas do seu in media res, ou melhor, o faz voltar à praia, litoral do mundo.

Eu descrevo-lhe o que é a costa, entre outras coisas frágeis que ela me explica:

a costa não é apenas o contacto da terra

e do mar;

o mesmo poderia dizer-se do fundo

do Oceano;

a costa é, sobretudo, a presença de um terceiro elemento,

o ar,

com seu papel fundamental;

e a energia do mar provém de movimentos ondulatórios que resultam do encontro da água e do ar.

(LLANSOL, 1984b, p. 33)

3 Digna de nota é a formulação final do texto de António Guerreiro (apud LLANSOL, 2002 , p. 80, negritos meus): "A comunidade surge assim como alternativa e resistência à pátria. A primeira é um espaço aberto e abrangente que compreende a errância e a compreensão universal; a segunda é uma máquina infernal de inclusões e de exclusões, de enraizamentos e de exílios. Sentir-lhes os efeitos é estar sujeito às formas patológicas com que ela exerce o seu domínio, a mais poderosa das quais é a nostalgia (etimologicamente, a doença da pátria). A lei da comunidade é o nomadismo e o devir anónimo, a lei da pátria é a fixação e a distinção. Contra o livro da pátria, este é o Livro da comunidade. Neste sentido, /este livro/ inscreve-se contra Os Lusíadas." 
Com isso, ao voltar para a praia, o texto llansoliano vai ao encontro controverso (SILVEIRA, 2008) destas e de "outras palavras que diziam,/ De amor e de piadosa humanidade" (Lus, IV, 92, 1-2) que preparam a voz do Velho, no Canto IV d'Os Lusíadas. Encontro da água e do ar: tempestades marítimas, encontro das decisões apaixonadas e da consciência: "Nenhum cometimento alto e nefando/ Por fogo, ferro, água, calma e frio./ Deixa intentado a humana geração./ Mísera sorte! Estranha condição!"(Lus, IV, 104, 58). Consequentemente, o que chama a atenção no excerto anterior não é a densidade da água portuguesa propiciadora da poética colonialista marítima e da partida sem volta que leva Portugal a amar um Fantasma. Aqui, o que promove a beleza dos dois excertos lidos anteriormente é mais a lembrança do Ar como catalisador de deslocamentos que a totalidade aquática dos Impérios:

Pelas fendas da paisagem, tornou-se perceptível um curso de ar que agitou de contentamento os ramos de dom arbusto:

daqui faço uma linha que me ata ao sol,

um traço para o solo firme,

uma seta que guardes no coração,

uma fenda para ver o mar.

(LLANSOL, 1984b, p. 156)

Assim, o desejado Rei dá lugar, depois de várias metamorfoses, através de um fluxo de ar, a uma nova escrita vegetal "no desenho de uma fina caligrafia,/ que o mar o ia deixando de levar a Alcácer Quibir," (LLANSOL, 1984b, p. 146). Como se a ficção, por meio da sua múltipla organização de planos temporais e geográficos, permitisse outra História: não a de um Rei que volta vitorioso e pleno de poder da batalha, mas a de um ser que não vai em direção à guerra.

Verifica-se em Maria Gabriela Llansol a ideia de que tal proposição acima demonstrada orientaria uma opção desprovida de relação com o Poder, já que abdicaria de uma sistematização do mundo organizada pela oposição e complementaridade entre Senhor e Escravo. Contudo, devo 
admitir que minha hipótese insiste em acreditar que mesmo no espaço da Comunidade do Cabo Espichel ("retida pelo pendor da escrita" - LLANSOL, 1984b, p. 135), lugar em que as beguinas e os outros dedicam-se à "arte da partida" (p. 136), o poder é imanente, na medida em que até mesmo sem procedimentos de hierarquização, as relações entre seres de diferença pressupõem modos e formas de lidar/interagir com o mundo, sua História, seu presente e suas Tradições. Para tanto, bastaria reforçar o título provisório que Llansol deu por algum tempo a O Livro das Comunidades: O Livro dos Poderes do Livro, isto é, um nome que evidencia a consciência de que também na Comunidade da Escritura, orientada pela palavra, são desenhadas manifestações poderosas, porque linguísticas e, portanto, de alguma maneira estruturantes de "sistemas simbólicos de poder"4.

Com isso, o projeto da transumância, o "outro lado da sua fidelidade" (LLANSOL, 1984b, p. 164) à causa amante, evoca o projeto não apenas do entrelugar, mas do entresser, inaugurando não mais uma política engendrada pelo fator humano como premissa, mas uma política possível da criação estética: harmonias e fluxos migratórios pelos diversos reinos e filos que têm vida no Mundo em que respira a Restante Vida:

Será a restante vida ouro, isto é, metamorfose escritural, força metálica de uma língua que, pouco a pouco, vai sendo dissolvida na água? Águas ambíguas, ora águas de Tejo-rio, ora águas já definitivamente poluídas.

(LLANSOL, 1984, p. 108)

O cerne da questão que envolve o humano em Llansol é amplamente discutido, tendo em vista que, nessa questão, estejam embutidos os termos que trazem à reflexão a própria condição humana e o que houve ao longo de sua história: como ignorar que a trajetória do Homem sobre a Terra não propiciou apenas avanço da técnica e a potencialidade das culturas, tendo utilizado para

\footnotetext{
${ }^{4}$ Conferir a obra O Poder Simbólico, de Pierre Bourdieu, na qual se analisa a interação de sistemas simbólicos ou não de poder, considerando três "estruturas estruturantes" (BOURDIEU, 2007, p.8): a arte, a religião e a língua.
} 
isso a contradição de, frequentemente, dizimar parte de sua própria espécie? Nesse sentido, a obra de Maria Gabriela Llansol impõe questões obsessivas sem necessariamente expô-las de forma tão evidente, de maneira a possibilitar que a legência seja chamada para quem ou o que, ali, perguntar por ela. Porque, como já foi dito, dentre as muitas cintilâncias do Livro, importa também que ele ofereça uma alternativa respiratória para o Mundo, e o conjunto dessas opções alargadas pelo escrever vai de encontro ao propósito humano ocidental. Em outras palavras: o humanismo, tido como fundamento da promessa e da latência da nossa espécie, é reavaliado pelo texto llansoliano. O crítico João Barrento parece concordar:

Em muito do que dissemos há uma leve sugestão de que, para nós conseguirmos um dia chegar a dizer o que é o humano neste texto, não podemos deixar de integrar nele os animais, que estão presentes como aqui se diz, juntamente com os humanos e com a casa. (...) $O$ humano não tem possibilidades nem condições de se alcançar em si mesmo e por si só, e aí os animais presentes, embora possa nem se falar de um animal em concreto, têm essa função de contribuir para uma modelação dos contornos do humano.

(BARRENTO, 2009, p. 65)

Esse ponto, nevrálgico para a delineação da outra paisagem já começada na "Geografia de Rebeldes", permite que seja colocado em perspectiva até mesmo o aspecto puramente humano da literatura, uma vez que, do seu ponto de vista, a arte da palavra (no sentido da sua pulsão estética) permite a interação num espaço em que somente seres dotados de certos tipos de compreensão e linguagem estariam presentes. Quando Pégaso, Coração do/de Urso, Alissubo, Prunus Triloba, Jade e outros começam a agir tanto nas atividades de escrita quanto nas de leitura e convivência, passa a existir nestes textos uma produção de sentido que alarga as expectativas convencionais dos chamados "realismos".

De qualquer forma, no que Llansol escreve é visível a relação conflituosa com o fator humano, embora importante também seja pensar que o 
seu texto adquire muito da feição conativa da linguagem, muito por causa do seu tom evocatório em relação ao próprio desempenho das figuras ao longo das imagens narrativas. Isso justificaria, por exemplo, a frequente presença de Monstros e outros híbridos latentes de forma bastante específica nesta segunda trilogia. Os mutantes, como explicou o prefácio d'O Livro das Comunidades, trazem a série do humano consigo, mas ultrapassam a sua fisicidade, seus contornos e delineamentos. Por outro lado, estão sempre à mercê, como que conscientes da sua necessidade de Misericórdia. Os Intensos não dispõem de individualidade tal qual a entendemos hodiernamente ou, pior, pósmodernamente. São dotados de uma aliança com o que defendem, entre eles mesmos e suas causas. E também porque estão sob a égide da (in)diferença é que serão abraçados como rebeldes.

As questões políticas congregadas ao fator linguístico estão presentes de maneira mais insidiosa em Da Sebe ao Ser, na ocasião em que Vê Gama luta contra o tédio e se percebe desafiado por Comuns e por João da Cruz. O nome da personagem de Llansol já demonstra argutamente por que lugar esta figura está atravessada: Vê Gama deve atentar para o que importa a um núcleo épico, a saber, sua genealogia, o sobrenome por meio do qual é reconhecido como um herói nacional proveniente, de certo modo, de uma ínclita família que n’Os Lusíadas se aponta: "Não menos cobiçoso de honra e fama,/ O caro meu irmão Paulo da Gama" (Lus, IV, 81, 7-8). É, portanto, na cartografia esvaziada do tédio pós-colonial que Vê Gama ganha o aspecto locutório do texto, provavelmente por causa de uma intenção narrativa de "vê-lo" falar e defender a usurpação, o roubo, o abuso e a barbárie autorizados pela dinastia que enfim deu ao mar aquilo que no passado foi o desejo ardente de futuro nas "naus a haver" que Pessoa legou à cultura por meio da sua Mensagem. Hannah Arendt, perguntada por Günter Gaus em entrevista (ARENDT, 2008, p. 31) sobre o que restaria da/e na memória sobre uma vida de exílio, responde o título do diálogo entre os dois alemães: "O que Resta? Resta a língua", no sentido de que nem mesmo as piores experiências coletivas seriam capazes de neutralizar o aprendizado primeiro que ensinaram tanto a consciência quanto o 
sentimento ao exercício do pensar em língua materna, ainda que essa língua seja hiperpotencializada pela política ou por interesses exclusivo-nacionalistas. Um clássico exemplo disso foi o uso que a ditadura salazarista fez d'Os Lusíadas e, muito provavelmente por isso, Llansol tenha dado a Vê Gama, numa de suas narrativas, o tom presunçoso, a "língua da arrogância" (LLANSOL, 1988, p. 84) que tem necessariamente a ver com outra linha de leitura do fogo: o navegador português, muito embora seja defendido por Vênus, tem muito da astúcia e da presunção de Marte.

É provável que, sob os efeitos de "sofrer a pena dos reconciliados (sacrifício espiritual, prisão ou desterro)" (LLANSOL, 1984b, p. 99), o Jorge Anés (uma versão de Jorge de Sena) de Llansol funcione como figura metonímica dessa língua obstinadamente procurada porque certamente enrouquecida desde que o outro Poeta, no seu último canto do livro, escreveu com pesar:

Falei nesta contradição a Jorge Anés, durante uma visita que pôde fazer-nos, e ele me aconselhou absoluto silêncio, pois se ele tinha de sofrer o fogo, que nós e nossos similares fôssemos guardados, e enterrados a seu tempo de vida normal no jardim,

(...) falamos contendo o movimento desnecessário dos lábios, e ele disse-me que o caminho era longo, mas que tivesse esperança,

pois maior do que nós

era a língua

que nos esperava;

disse-lhe a sorrir,

que ela estava presa num ramo,

e ele disse-me

que eu tinha uma linguagem feminina e descalça,

mas que não era ainda a língua.

- Que hei-de fazer? - perguntei-lhe. E ele respondeu-me que era preciso dar tempo ao tempo,

o fogo ao fogo,

a cidade de Lisboa à cidade de Lisboa,

o Tejo ao Tejo, 
e o mínimo movimento ao grande movimento da nova espécie.

(LLANSOL, 1984b, p. 101-102)

Assim, a espera e a aposta pela nova espécie são o que proporcionam os primeiros traços de um mapeamento possível nessas grafias narrativas do Mundo. Nelas, surge uma recuperação e uma reapropriação doutros passados não sentidos puramente como nostalgia: é que no "grande movimento da nova espécie" as metamorfoses do fogo (que afinal são as metamorfoses da energia que move o espírito da Restante Vida) permitem que "aqueles que devem morrer para que a língua viva devem ressuscitar entre si" (LLANSOL, 1984b, p. 103). Esse renascimento precisaria obedecer ao princípio do espaço litoral, também incerto e provisório, típico lugar contrário ao das assertivas e da Pátria. Nesta praia llansoliana, meditam Camões e Sena, mas também outros companheiros de língua, linguagem e descendência que tão bem cabem e perdem-se em versos desta primeira das "Oito Meditações à beira do Pacífico":

Sobre esta praia me inclino.

Praias sei:

Me deitei nelas, fitei nelas, amei nelas

com os olhos pelo menos os deitados corpos

$(\ldots)$

Do Atlântico ondas rebentavam plácidas

e o delas ruído às vezes tempestade

que em negras sombras recurvava as águas

me ouviram não dizer nem conversar

mais do que os gestos de tocar e ter

na tépida memória as flutuantes curvas

de ancas e torsos, negridão de pêlos,

olhos semicerrados, boca entreaberta,

pernas e braços se alongando em dedos.

Aqui é um outro oceano.

Um outro tempo.

$(\ldots)$ 
(SENA, 1989b, p. 235)

O texto de Jorge Fernandes da Silveira que abre O Tejo é um Rio Controverso indica muito do que devia ser vislumbrado por Llansol em Camões. Porque Inês de Castro e o Adamastor estão presentes na seleção camoniana que atravessa o humano, considerando neles o motivo da própria ruína, a saber, o Amor. E se, por um lado, o grande poeta da Língua não os esquece, Maria Gabriela também encontra em $\mathrm{Da}$ Sebe ao Ser espaço para lançar mão dos Golém, espécie de criaturas disformes consideradas monstros de lama e depois monstro de pedra ou o "grande golém das naus, que trouxera até aquele embarcadouro o conceito sensual da caravela e da experiência da travessia dos mares" (LLANSOL, 1988, p. 25). Nessa experiência com os "seres-limite" que avançam sobre a destituição contínua das imagens prosaicas do mundo, dois lugares são testemunhos antes do epílogo: o Monte Espichel (não apenas Cabo, mas monte ainda vinculado ao ascetismo da Subida do Monte Carmelo, de São João da Cruz, isto é, o Monte Espichel também pressupõe uma jornada da alma) e o Jardim ("o jardim que o pensamento permite" - encontro com o Fantasmamor da cultura portuguesa tornado arbusto, um dom, metonímia do que o texto transforma).

Esses Pobres, notadamente ocupantes de lugares diferentes daqueles das insígnias, funcionam textualmente como figuras inesquecíveis, nem sempre dotadas de misericórdia, mas aprendentes e, de certa maneira guiados por Juan (de la Cruz), que "chefiava um bando de pobres inconformistas e ambiciosos, que queriam fazer a subida do mundo humano" (LLANSOL, 1988, p. 148, negritos meus). Nas interventivas dessa comunidade é possível receber as visitas de outros irmãos que a História ou a relação TempoPoder não consegue marginalizar no texto. O contínuo dessa neogeografia, à beira da escrita, vislumbra e deseja uma inequação na qual a variável esperança seja maior que a outra, o desesepero: 
Mas para me consolar sugeriu que talvez houvesse jardins que fossem como as chaves, só que não sabia como despertá-los da sua longa sonolência, embora, de certeza, em cada chave esquecida estivesse escondida uma porta que se não abre.

Suspeito que este monge faz parte do bando de judeus e de ciganos cremados em Dachau, em Auschwitz, em Treblinka; suspeito que os bandos criam o sangue e que o sangue cria a aflição onde estou. Havia muitas plantas espinhosas que chegavam do campo de batalha.

(LLANSOL, 1988, p. 114)

É por causa desse desejo de humano que o texto llansoliano escapa da valoração épica, dando aos seus ramos, tão profundamente presentes em $D a$ Sebe ao Ser, uma roupagem destituída, ainda que estejam presentes no livro as personagens povoadoras dos dez cantos mais efetivos da cultura portuguesa e a sua marca d'água. Fica evidente, portanto, que para Llansol o sentido da epopeia coincide com certo ethos do mundo e que, por isso, os versículos contidos em "O canto de Comuns, o Pobre, está moribundo" ocupam páginas das mais belas e contemporaneamente importantes:

Nesta situação triste e extrema,

o bando de camponeses das silésias, de judeus e ciganos de dachau, de almocreves, de marinheiros da rota das Índias, de

soldados rasos e comerciantes de canela, de hereges

e heterodoxos,

havendo-me reencontrado o rasto,

entrou no quanto ou no livro que se deixava morrer.

O livro agonizante era, sem dúvida, o livro que deveria ser dirigido a esta nação de pobres; não fiquei perplexa, nem desconcertada,

andando nós todos,

como andamos

ligados ao fio da morte,

que vai com o tempo, 
e nos há-de conduzir à ilha; das minhas mãos às mãos dos do bando, passa, pois, um fio corre sempre e que, quando começamos a avançar com rapidez, descendo a Serra, elevou o livro nos ares,

tal Pégaso de papel,

e aí o deixou preso à nossa história, à nossa insustentável

vontade de viajar de paisagem em paisagem,

até nos encontrarmos sozinhos

para desaparecer.

Foi nesse instante que uma criança, a quem ensináramos a manejar o fio que mantinha voando o Pégaso alado, perguntou a outra, e depois ainda a outra, e finamente a mim:

- Um homem a morrer chama-se moribundo, e a um livro?

Respondi-lhe que tal nome ainda não existia, mas que tudo haveria de depender do despojamento das nossas categorias mentais

E da misericórdia que alcançássemos como pobres.

Como a visse triste com a resposta, e o livro puxasse pelo fio, mandeia ter com Comuns que este talvez soubesse o nome do que jamais seria lido.

E vi Comuns fazer-lhe sinais: - Lusíadas - disse - é o nome deste papagaio de papel. A criança riu-se

com o nome dado a Pégaso,

e eu deixei-a com o fio.

(LLANSOL, 1988, pp. 137-138.)

Se, afinal, a trilogia sobre o litoral do mundo coincide, em parte, com um decalque do sentido mítico d'Os Lusíadas - salvo a nado do simbólico naufrágio -, operado pelo cavalo de asas e pela figura da criança questionadora, também é verdade que sobressaem aqui inúmeros fios e elos dos quais nem mesmo o texto llansoliano pode se livrar, na medida em que se apropria deles para retomar outros novelos de narrativa e dar o passo seguinte para a textualidade. $\mathrm{O}$ canto funâmbulo, assim, importa muito não só porque o seu sentido "o deixou preso à nossa história", mas porque o próprio declínio épico evoca o declínio do que fosse desejo de verdade para o coletivo: honra e glória. Um 
pouco daquilo que Sloterdijk (2002) identifica como descarga do indivíduo em processos de identificação com figuras que encarnam o heroico dilatador. Parece ser o desejo da escrita de Llansol estar atenta aos fios que se confundem e prendem "à nossa história" e, nesse sentido, disso deriva a vontade de, no encontro do diverso, enfrentar o tão referido nó de paradigma frontalmente inatacável.

O Litoral do mundo: lugar de costa, para fora da língua, à margem do mundo. Sobre o texto llansoliano, não há como duvidar: trata-se de uma jovem escrita rebelde do mundo. Rebelde não apenas porque sua outra e nova escrita do mundo adota o periférico, o limítrofe e o errante como potência, mas evidentemente porque $\mathrm{o}$ resultado dessa proposta não se apresenta domesticado ou servil a quaisquer preceitos estéticos vigentes no contexto histórico das suas publicações. Em outras palavras: o texto de Llansol não se enquadra em nenhum rol de tipificações literárias e por isso sua rebeldia, enquanto discurso, reforça a diferença necessária para a existência da política.

\section{REFERÊNCIAS BIBLIOGRÁFICAS:}

\section{1- DE LLANSOL:}

LLANSOL, Maria Gabriela. A restante vida. Porto: Afrontamento, 1982.

LLANSOL, Maria Gabriela. Causa Amante. Lisboa: A Regra do Jogo, 1984b.

LLANSOL, Maria Gabriela. Contos do Mal Errante. Lisboa: Rolim, 1986.

LLANSOL, Maria Gabriela. Da sebe ao ser. Lisboa: Rolim, 1988

LLANSOL, Maria Gabriela. Finita. Lisboa: Assírio \& Alvim, 2005.

LLANSOL, Maria Gabriela. Na Casa de Julho e Agosto. Porto: Afrontamento, 1984.

LLANSOL, Maria Gabriela. O Senhor de Herbais. Lisboa: Relógio d’Água, 2002.

LLANSOL, Maria Gabriela. Um Falcão no Punho. Lisboa: Relógio d’Água, 1998. 


\section{2- SOBRE LLANSOL:}

BARRENTO, João. O que é uma Figura? Lisboa: Mariposa Azual, 2009.

LOPES, Silvina Rodrigues. Teoria da des-possessão. Lisboa: Black Sun, 1988.

MENDES, João. “No espaço Llansol (conversa a propósito de Lisboaleipzig)". Lisboa: Público/ Leituras, 18 de janeiro de 1995.

\section{3- OUTRAS:}

ARENDT, Hannah. A promessa da política. Rio de Janeiro: Difel, 2005.

ARENDT, Hannah. Compreender. São Paulo: Companhia das Letras, 2008.

BOURDIEU, Pierre. O Poder Simbólico. Rio de Janeiro: Bertrand Brasil, 2007.

CAMÕES, Luís Vaz de. Os Lusíadas. Edição organizada por Emanuel Paulo Ramos. Porto: Porto Editora, S/D.

LOPES, Silvina Rodrigues. Literatura, defesa do atrito. Lisboa: Vendaval, 2003.

MACEDO, Sebastião E. de S. As Metamorfoses do Sujeito em Arte de Música de Jorge de Sena. Dissertação de Mestrado em Letras Vernáculas. Rio de Janeiro: Faculdade de Letras, UFRJ, 2009.

SENA, Jorge de. Poesia III. Lisboa: Edições 70, 1989b.

SILVEIRA, Jorge Fernandes da. O Tejo é um Rio Controverso. Rio de Janeiro: Sette Letras, 2008.

SLOTERDIJK, Peter. Mobilização Copernicana e Desarmamento Ptolomaico. Rio de Janeiro: Tempo Brasileiro, 1992.

SLOTERDIJK, Peter. O desprezo das massas - Ensaio sobre lutas culturais na sociedade moderna. São Paulo: Estação Liberdade, 2002.

SLOTERDIJK, Peter. Regras para o parque humano - uma resposta à carta de Heidegger sobre o humanismo. São Paulo: Estação Liberdade, 2000. 